\title{
Low Cost Solar Powered Telecenters for Malaysian Rural Areas: Case Study in Pos Sinderut, Pahang, Malaysia
}

\author{
M.D. Ibrahim ${ }^{1}$, S. Zainal ${ }^{2}$ and A.K. Othman ${ }^{3}$ \\ ${ }^{1}$ Faculty of Engineering, Department of Mechanical and Manufacturing Engineering, Universiti Malaysia Sarawak \\ ${ }^{2}$ Faculty of Engineering, Department of Electrical and Electronic Engineering. Universiti Malaysia Sarawak \\ *Corresponding author E-mail: imdanial@unimas.my
}

\begin{abstract}
The main objective of this project is to design and analyze the cost benefits solar PV system for rural telecenter. The project focused on designing the main solar system and solar panel energy performance based on translucency. The task that was carried out in this project was the selection of the suitable system that will suit the operation well while keeping the design cost as low as possible. In this project, the design of the solar panel system was focused on the electric loads and its cost benefit. Homer software was used to evaluate the solar panel system. Meant for ways of communications for indigenous people, the Solar Photovoltaic system is one of the popular solution for off-grid rural community power supply. The optimized combination for a particular rural site can be predicted based on NASA's data of Solar Global Horizontal Irradiance (GHI). In this project, Pos Sinderut was chosen as the site, and the data load was measured. In our preliminary findings, it was found that the model on site was not suitably designed and maintained. The data parameters that was used for the on-site installed model was also not possible to be calculated when the model was simulated using Homer Software. As a result, we proposed a new model design by optimizing the load of VSAT and charging station based on the amount of solar PV and batteries that was supplied. This paper shows the significance of preliminary designs based on the irradiance and the usage load of the specific site before any installation should be commenced. It also showed how the site should be maintained properly in order to ensure a chosen site is sustainable for the rural community, post-installation.
\end{abstract}

Keywords: Solar Panel System, rural areas, Homer Software, cost benefits, PV system, energy performance.

\section{Introduction}

Due to the growing demand for energy with a cost-effective method with respect to the environmental issues and social priorities, there is a need for a sustainable energy system. Such system provides the possibility to move toward sustainable development and getting all people of the world to effective, accessible, clean and safe energy. Today, about 1.3 billion people (mainly in developing countries and rural areas) do not have access to electrical energy [1].

Electrification is one of the infrastructures required by the people in the world for the benefits of education, health, industries, employment, transportation and others. However, it is estimated that 85 percent of the 1.2 billion people in the world living without access to electricity reside in rural areas, which is attributable to the marginalization of the poor as well as their long distance from established electrical grids.

In Malaysia, 809 out of more than 10,000 schools lack 24hrs electricity. Most of these school are located in Sabah and Sarawak [2]. The important components of rural electrification in Malaysia are renewable energy (RE) based power generation, optimization, hybrid power, system integration, and monitoring solar irradiance in Malaysia is $1,643 \mathrm{kWh} / \mathrm{m}^{2}$. Thus, this country is among the leading users of solar PV in the world [3].

Sabah and Sarawak encounter high volumes of rainfall that average 3,540 $\mathrm{mm} /$ year. This large amount of water can be a source of hydro power [4]. Moreover, the northern wind in the area reaches roughly $15 \mathrm{~m} / \mathrm{s}$. International interest has increased with respect to rural electrification by hybrid renewable systems, including largescale PV, wind, and hydro. The combination of PV, wind, hydro and biomass energy may enhance rural electrification significantly while reducing environmental pollution [5]. Thus, the application of hybrid power generation is promising especially in rural areas, where transport and communication are difficult [6].

\subsection{Homer software}

Homer software simulates the behavior of energy-power delivering systems and their cost during the life cycle. In simulation, Homer software describes technical specifications and cost during the life cycle of renewable sources system for hourly data per year. The next step is the calculation of the system configuration and the strategy for operation of the power delivery parts. The software is to inspect how these parts work for the calculated year. This is the amount of money spent for a system and the costs of services over its life cycle. When the system is modelled, and each component is being set, the calculation can be conducted. The software calculates the options that the users have, which were being set by deciding the search space and choose the best option of sizing of all the components that is in the system. 


\section{Standalone photovoltaic system}

\subsection{Only- PV systems performance evaluation}

In stand-alone systems, the productivity yield is not so used as a system quality proved. However, some interesting results can be outlined. If the load consumption is low for whatever the reason is, batteries prone to overcharge. Then, the PV array generation is regulated or even interrupted to protect the batteries and the productivity yield is reduced because of full energy stored. Considering this, the productivity yield in off-grid systems includes also the utilization level of the system, which is not a technical quality indicator but a valuable parameter for the evaluation of an electrification program. In figure 1, mean productivity yield values registered on PV systems are shown. Basic design data are summarized in table 1 [7].

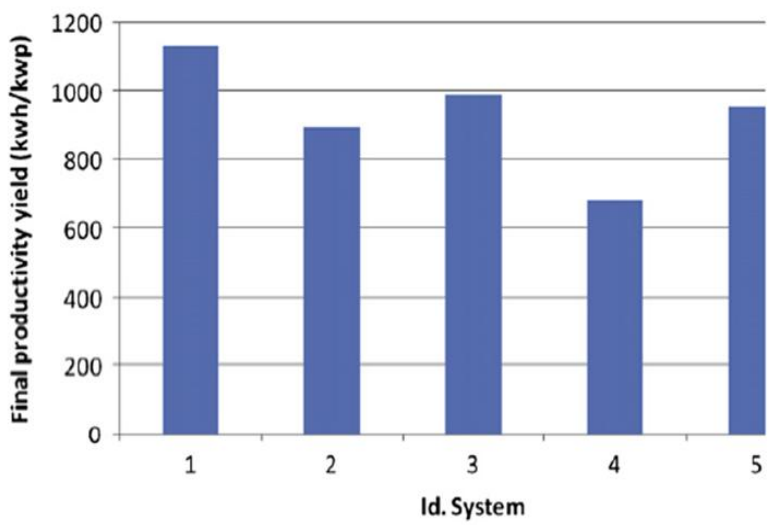

Fig. 1: PV system productivity yield

Table 1: Design Data of Collective PV Installation

\begin{tabular}{|c|c|c|c|c|c|c|}
\hline Id. & Location & $\begin{array}{l}\mathrm{N} \\
\text { households }\end{array}$ & $\begin{array}{l}\text { Nominal system } \\
\text { voltage }\left(V_{D C}\right)\end{array}$ & $\begin{array}{l}\text { PV gen } \\
(\mathrm{Wp})\end{array}$ & $\begin{array}{l}\text { Wp per } \\
\text { household }\end{array}$ & $\begin{array}{l}\text { Battery } \\
\text { bank (A h) }\end{array}$ \\
\hline 1 & $\begin{array}{l}\text { El } \\
\text { Angosto }\end{array}$ & 19 & 48 & 2100 & 110 & 900 \\
\hline 2 & $\begin{array}{l}\text { La } \\
\text { Ciénaga }\end{array}$ & 23 & 48 & 3000 & 130 & 1200 \\
\hline 3 & $\begin{array}{l}\text { San } \\
\text { Francisco }\end{array}$ & 10 & 48 & 1800 & 180 & 900 \\
\hline 4 & $\begin{array}{l}\text { San Juan } \\
\text { y Oros }\end{array}$ & 19 & 48 & 2100 & 110 & 900 \\
\hline 5 & $\begin{array}{l}\text { Timón } \\
\text { Cruz }\end{array}$ & 13 & 48 & 1500 & 115 & 900 \\
\hline
\end{tabular}

\subsection{Design and sizing}

In Pos Sinderut site, the standalone Photovoltaic (SAPV) systems are used. These SAPV are electrical power generating units energized by PV panels which are independent of the utility grid [8]. These systems are primarily used in remote areas where the installation of power transmission lines is expensive due to the terrains difficulties or environmental concerns [9]. The power generated by PV panels fluctuates due to the random nature of solar energy. Therefore, SAPV system needs power conditioning and battery bank for storage of generated energy. Besides PV panels, a complete SAPV system consists of different components such as charge controllers, battery bank and power inverters.

The system components can be selected on the basis of individual needs, type of load, location, climate and expectations. The proper design and sizing of PV systems and its sub-systems is required to utilize the solar energy resources in an economical and efficient manner [10]. Due to that reason, the meteorological data generation and utilization, optimization scenarios based on different meteorological data, criteria of size optimization and different size optimization techniques could be taken into account for the entire design and size optimization of a SAPV system.

\subsection{Sensitivity analysis of $P V$ system parameters}

The fuel consumption rate was compared versus diesel generator rated power capacity at different load factors. The PV/diesel life cycle cost ratio against cost of the PV array and diesel with energy demand were also analyzed. The comparison of PV module efficiency with generation cost, energy payback time and $\mathrm{CO}_{2}$ emissions were also conducted. Cameron et al. used Monte Carlo and fitted effects for N-way factorial for uncertainty analysis of total solar radiation on a south-west facade building integrated PV system [11]. Ellis analyzed power outputs of different PV models with different PV module technologies at daily and monthly average yearly basis [12].

\subsection{Economy analysis}

Economic analysis is an organized formulation to find out the optimum solution of specific objective under the given assumptions and constraints. In SAPV systems, the economic evaluations are being carried out to quantify the projected costs incurring from the system lifetime. Typically, two different types of costs are expected from solar PV systems, namely capital costs and future costs. Capital costs are acquisition costs incurred prior to the occupation of the facility including the purchasing cost of each system component and installation cost of the project. Approximately 60 to $80 \%$ of system life cycle cost is locked in this phase. Future costs are the forthcoming expenditures projected from the system operation [13]. Future costs are further classified into two parts, such as recurring and nonrecurring costs.

\section{Methodology}

\subsection{Design}

This paper focuses the design and economic analysis for the rural telecentre in Malaysia. From this, some comparison have been made between the site model and the Homer model. Model site is the complete design for the previous data of this research, which is the model that is already installed at some of rural areas (Pos Balar, Pos Gob, Pos Lenjang and Pos Sinderut).

Figures 2 and 3 shows the comparison between model from the site and model from the Homer software. Figure 2 shows the installed system at site provided by the contractor in-charged of the sites development. Figure 3 shows the setting of every parts of Model Homer in Homer Software.

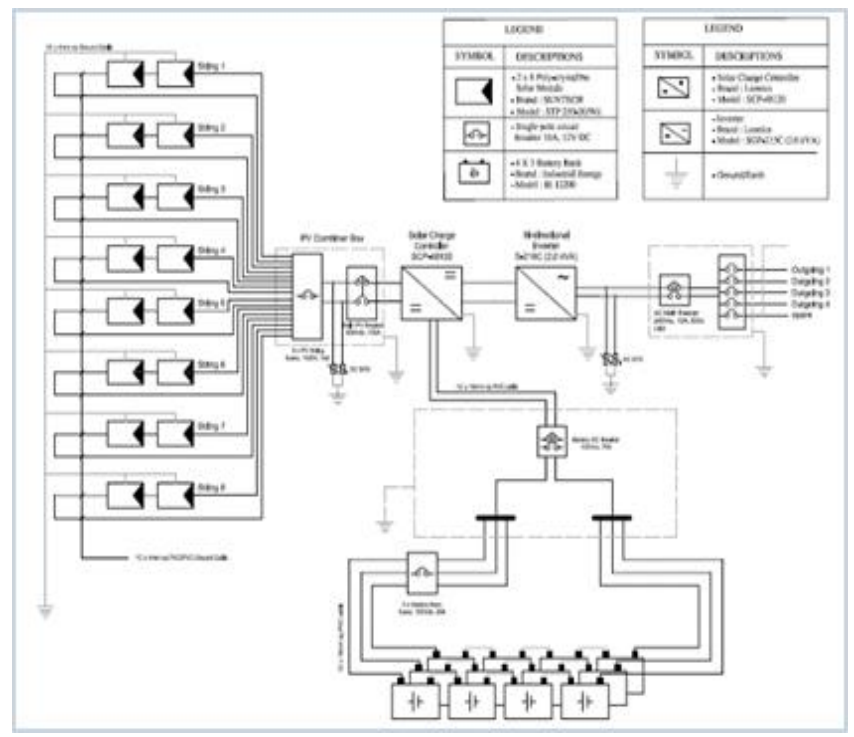

Fig. 2: Model Site from Helios 


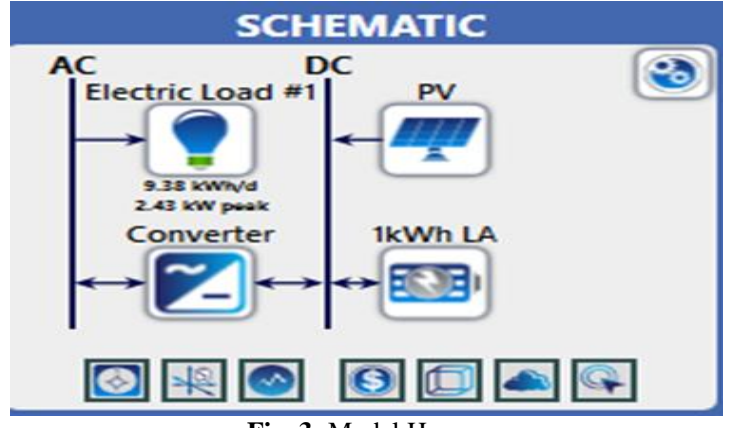

Fig. 3: Model Homer

\subsection{Solar PV}

At the targeted site in this research, the Suntech Power STP25020/Wd, $250 \mathrm{~W}$ solar PV is used. This is because the module of crystalline silicon PV panels has higher performance and its prices is reasonable. The achievable efficiency for this module is up to $15.4 \%$ through advanced cell technology and manufacturing capabilities. This module performance is also excellent under low light conditions and reliable quality leads to a better sustainability even in harsh environment. Figure 4 shows the setting for the solar PV resembling the aforementioned used solar PV on site in Homer.

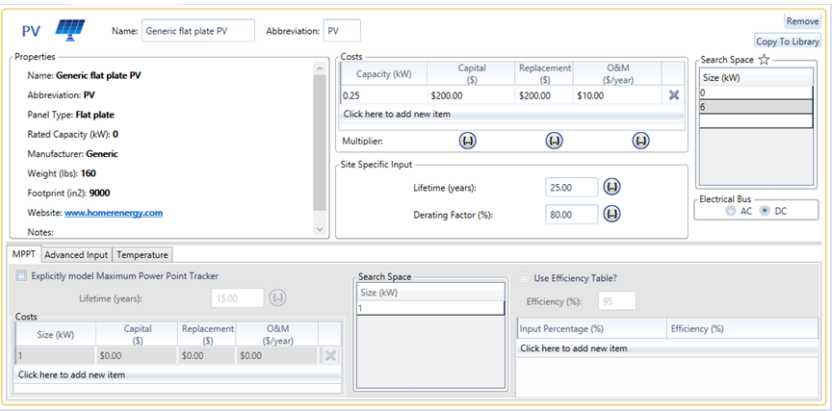

Fig. 4: Solar Photovoltaic Setting in Homer Software

\subsection{Batteries}

From Homer Software, the suitable batteries that can be used is Trojan $12 \mathrm{~V}$ flooded battery. For the batteries, flooded battery can be used because this battery suitable for our weather in Malaysia and it is also cheaper. Flooded battery sustains performance providing exceptionally longer battery life. The setting is shown in Figure 5 below.

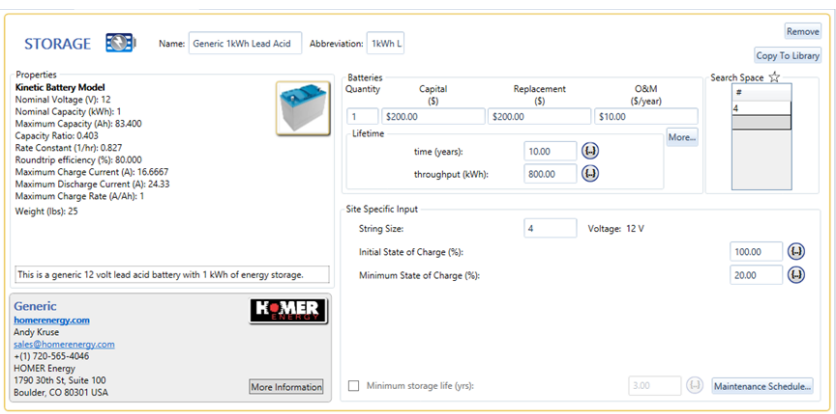

Fig. 5: Battery Setting in Homer Software

\subsection{Inverter}

In this analysis, the $3 \mathrm{~kW}$ sized inverter is used because if the $2 \mathrm{~kW}$ inverter is used as proposed by the contractor, the analysis using Homer software could not conduct the simulation. This is belived due to the excessive electrical load that is being used by the Telecenter. Figure 6 shows the inverter setting being set in Homer software based on the new proposed inverter kW settings.

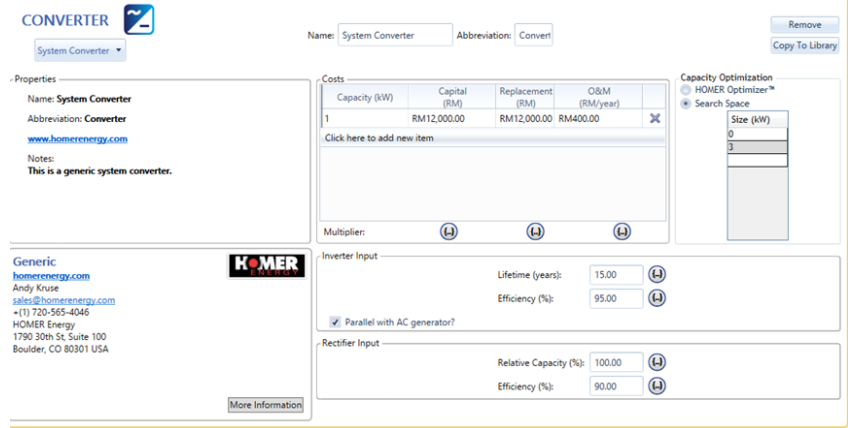

Fig. 6: Inverter Setting in Homer Software

\subsection{Site verification}

The load was verified by observing the community Institute of Social Informatics and Technological Innovations (ISITI) Telecentre usage. Preliminary finding shows that the previous after purchasing loads data (on site contactor model) is insufficient to support the load suggested previously. Homer also suggested that a bigger PV system needs to be installed in order to ensure that the telecentre is operating solely on solar. The models created using Homer will then be verified by the newly observed load. Figure 6 shows the site locations in Malaysia conducted by UNIMAS while the site chosen as a subject in this research was Pos Sinderut, located at the outskirt of Pahang and Selangor.

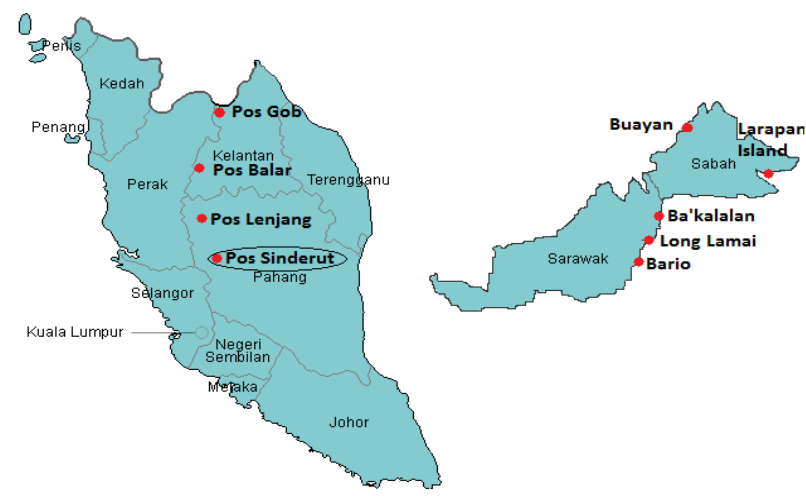

Fig. 6: Sites in Malaysia

\section{Result and discussion}

From this research, Table 2 shows that there are two different data loads for Pos Sinderut electrical load. The loads are measured loads on-site and proposed loads. The data of daily consumption for standalone electrical load was designed. The Pos Sinderut telecentre has various electrical equipment such as stand fan, ceiling fan, personal computer assembly, television, very small aperture terminal (VSAT), projector, room lights, and charging station. This electrical load was calculated every minute for the whole year, depending on which component is being used during that hours. These differences in loads shows that the results need to be verified on site to know why the differences are there. For the proposed load profile, we have reduced the load profile from the measured load profile on-site to make sure the cost of system design is as low as possible.

Table 2: Comparison Electric Load Parameters

\begin{tabular}{|c|c|c|}
\hline $\begin{array}{ll} & \text { Electric Loads } \\
\text { Parameters }\end{array}$ & Measured Load On-Site & Proposed Load \\
\hline Load Profile & $10.96 \mathrm{kWh} / \mathrm{d}$ & $7.81 \mathrm{kWh} / \mathrm{d}$ \\
\hline $\begin{array}{l}\text { Solar GHI Resource (Annual } \\
\text { Average) }\end{array}$ & $5.28 \mathrm{kWh} / \mathrm{m}^{2} / \mathrm{d}$ & $5.28 \mathrm{kWh} / \mathrm{m}^{2} / \mathrm{d}$ \\
\hline Solar Photovoltaic & $5 \mathrm{~kW}$ & $4 \mathrm{Kw}$ \\
\hline Battery & 12 Pieces (3 strings) & 8 Pieces (2 strings) \\
\hline Inverter & $3.00 \mathrm{~kW}$ & $3.00 \mathrm{~kW}$ \\
\hline
\end{tabular}




\subsection{Two different load profile}

Figure 8 shows the electrical load for daily profile, seasonal profile and yearly profile graphs. From Figure 8, the daily profile graph for on-site load (load preliminary) shows that from the first hours until $7 \mathrm{am}$ the load is $0.446 \mathrm{~kW}$. Then from $8 \mathrm{am}$, the load decreases until $0.281 \mathrm{~kW}$. Then, starting from $9 \mathrm{am}$ until $12 \mathrm{pm}$, the load increases to $0.857 \mathrm{~kW}$. This is believed because during that hours, the electricity load is being used for the community during their morning session. Then, at 1pm, the electrical loads decrease constantly until $6 \mathrm{pm}$. Starting from $7 \mathrm{pm}$ to $10 \mathrm{pm}$, the electrical load constantly increases, ranging between $0.341 \mathrm{~kW}$ to $0.358 \mathrm{~kW}$. At $11 \mathrm{pm}$, the load is constantly used until $7 \mathrm{am}$. This is most probably because the Telecenter's electrical load is supposed to be being used for night lightings.

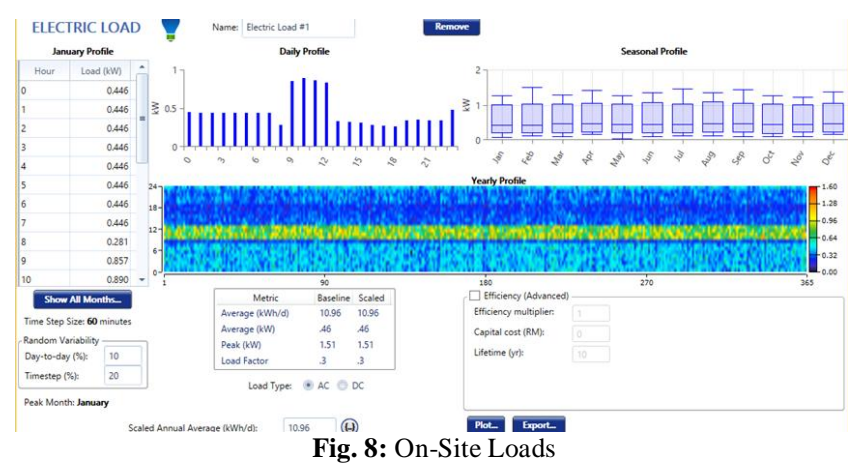

Figure 9 shows the proposed loads. The irradiance is based on the data from NASA's data of Solar Global Horizontal Irradiance (GHI) based on the coordinate found when the site was visited. The daily load profile for the first hour until $6 \mathrm{am}$ is $0.085 \mathrm{~kW}$. Then from $7 \mathrm{am}$ to $8 \mathrm{am}$, no load for that hours because the telecentre is not being used by the community and the light is off when there is sunlight in the early morning. From 9am, the load increases to $0.845 \mathrm{~kW}$ because during these hours, the charging station is starting to being used. For $10 \mathrm{am}$ to $3 \mathrm{pm}$ the load increases because during this time, the VSAT is additionally being used and electrical load is consumed. The load increases at $4 \mathrm{pm}$ because during that hours the community used too many devices such as VSAT and charging station that have higher loads. At $5 \mathrm{pm}$ to $11 \mathrm{pm}$, the load was lower because VSAT is not being used while only charging station are used during night because there were no activities at the telecentre.

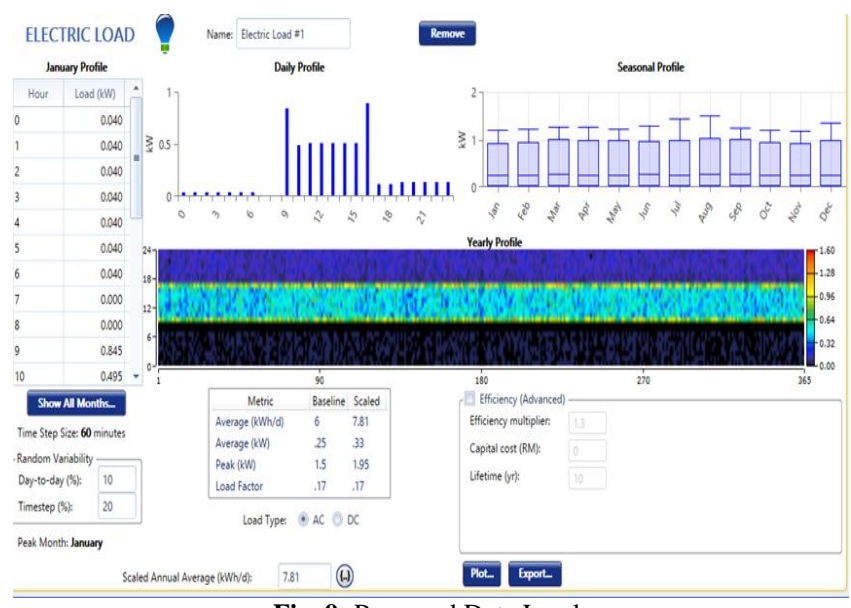

Fig. 9: Proposed Data Loads

From these two figures, a similar pattern was observed. This supports the fact that the proposed load profile is acceptable as a load profile for Pos Sinderut. The load for Pos Balar, Pos Gob, and Pos Lenjang might be similar to that of Pos Sinderut, however, it is better to have a site visit before a system is to be designed.

\subsection{Total net present cost for modified load}

Figure 10 shows the graph of net present cost by cost types for onsite load. Figure 11 shows the graph of net present cost by cost types for proposed load. From this two different graph, the net present cost by cost type is higher than the proposed load. Table 3 shows the net present cost for on-site load and proposed load with differences in values of parameters. The proposed load is observed, with $4 \mathrm{~kW}$ values of Solar Photovoltaic, $3 \mathrm{~kW}$ of inverter and 2 strings of batteries is suitable for next projects. This is because, the net present cost is RM128, 225.00 much lower than on-site load (available load previously designed without the usage of Home software).

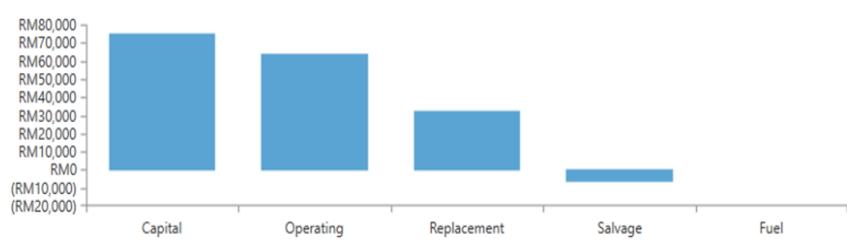

Fig. 10: Graph of Net Present Cost by Cost Types for On-Site Loads

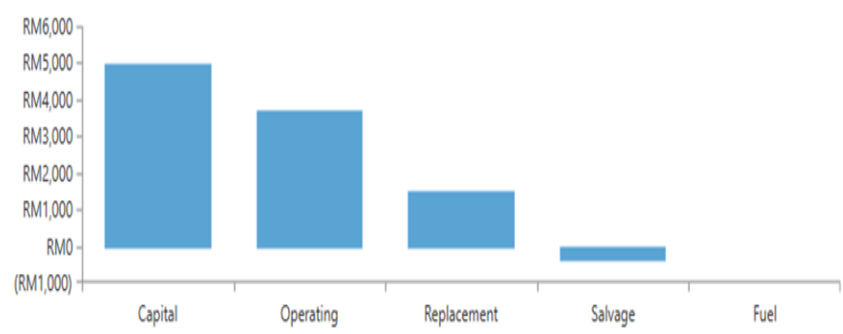

Fig. 11: Graph of Net Present Cost by Cost Types for Proposed Loads

Table 3: Cost Summary Comparison

\begin{tabular}{|c|c|c|}
\hline $\begin{array}{l}\text { Electric Loads } \\
\text { Components/Parameters }\end{array}$ & $\begin{array}{l}\text { Measured Load On-Site } \\
\text { (RM) }\end{array}$ & Proposed Load (RM) \\
\hline Total Net Present Cost & $166,365.00$ & $128,225.00$ \\
\hline Initial Cost & 75,600 & $64,800.00$ \\
\hline $\begin{array}{l}\text { Solar Photovoltaic Capital } \\
\text { Cost }\end{array}$ & $18,000.00$ & $14,400.00$ \\
\hline Battery Capital Cost & $21,600.00$ & $14,400.00$ \\
\hline Inverter Capital cost & $36,000.00$ & $36,000.00$ \\
\hline
\end{tabular}

\section{Conclusion}

This research focuses on the design and economic analysis of PV system for the rural area. From this, some comparison have been made between the model site (on-site load) and homer model (proposed load). Model site is the complete design for the on-site data of this research, which is the model that is already installed at the rural areas (Pos Balar, Pos Gob, Pos Lenjang and Pos Sinderut).

Homer model is modeled using homer software. Homer software simulates the behavior of energy-power delivering systems and their cost during the life cycle. This is the amount of money spent for a system and the costs of services over its life cycle. When the system is modeled, and each component is being set, the calculation can be conducted. Software calculates the options that the users have, which were being set by deciding the search space and the best option of sizing of all the components that is in the system is chosen. There is not a way to modify the current available battery specification based on the design that we want. A lot of assumptions are also needed to make sure the model can support the electrical load. From that, the on-site load have been modified by reducing the usage of VSAT and charging station that have higher load. There is also a possibility that the GHI resources from NASA are inaccurate or may have been a lot lower than the real GHI from the site. 


\section{Acknowledgements}

The present work was partially funded by UNIMAS Special Grant Scheme, Grant No: F02/SpGS/1408/16/9, Ministry of Rural and Regional Development, Department of Orang Asli Development, GrantNo: GL (I03)/07/2013/JAKOA (07), and Universiti Malaysia Sarawak.

\section{References}

[1] M. Mohammadi et al. (2018) Optimal planning of renewable energy resource for a residential house considering economic and reliability criteria. Electrical Power and Energy Systems 96 (201) 261-273

[2] Mahmud AM (2010) Evaluation of the solar hybrid system for rural schools in Sabah, Malaysia. In: The proceedings of the 2010 IEEE international conference on power and energy (PECon), 29 Nov-1 Dec, 2010, Sunway Resort Hotel \& Spa, Kuala Lumpur, Malaysia, pp 628-633

[3] Chua SC, Oh TH (2010) Review on Malaysia's national energy developments: key policies, agencies, programmes and international involvements. Renew Sustain Energy Rev 14(9):2916-2925

[4] Pimentel D (2008) Renewable and solar energy technologies: energy and environmental issues. In: Biofuels, solar and wind as renewable energy systems. Springer, Berlin

[5] Afshar O, Saidur R, Hasanuzzaman M, Jameel M (2012) A review of thermodynamics and heat transfer in solar refrigeration system. Renew Sustain Energy Rev 16(8) 5639-5648

[6] Shiroudi A, Rashidi R, Gharehpetian GB, Mousavifar SA, Foroud AA (2012) Case study: simulation and optimization of photovoltaic-wind-battery hybrid energy system in Taleghan Iran using homer software. J Renew Sustain Energy 4:053111

[7] Messenger, R. A., \& Ventre, J. (Eds.). (2004). Photovoltaic system engineering (2nd ed.): CRC Press, Boca Raton, FL.

[8] Patel, M. R. (2006). Wind and solar power systems: design, analysis, and operation. $2^{\text {nd }}$ ed. CRC Press, Boca Raton, FL, USA, 1-472.

[9] Kaabeche, A., Belhamel, M., \& Ibtiouen, R. (2011). Technoeconomic valuation and optimization of integrated photovoltaic/wind energy conversion system. Solar Energy, 85(10), 2407-2420.

[10] Loutzenhiser, P., Manz, H., Felsmann, C., Strachan, P., Frank, T., \& Maxwell, G. (2007). Empirical validation of models to compute solar irradiance on inclined surfaces for building energy simulation. Solar Energy, 81(2), 254-267.

[11] Cameron, C. P., Boyson, W. E., \& Riley, D. M. (2008). Comparison of PV system performance-model predictions with measured PV system performance. Proc 33rd IEEE PVSC, 11-16 May, San Diego, CA, USA.

[12] Ellis, B. A. (2007). Life Cycle Cost, The Jethro Project Report, Techwatch Report TSW, 1-8.

[13] Rubin, E. S., Yeh, S., Antes, M., Berkenpas, M., \& Davison, J. (2007). Use of experience curves to estimate the future cost of power plants with $\mathrm{CO} 2$ capture. International Journal of Greenhouse Gas Control, 1(2), 188-197. 